\title{
Modeling Co-optimization of an Enterprise's Production Capacity, Retail Sale and Advertising
}

\author{
Sherstennikov Yuriy, Yakovenko Aleksandr \\ Economy faculty, Oles Honchar Dnipro National University, Dnipro, Ukraine \\ Email address: \\ Hm001@ukr.net (S. Yuriy)
}

To cite this article:

Sherstennikov Yuriy, Yakovenko Aleksandr. Modeling Co-optimization of an Enterprise's Production Capacity, Retail Sale and Advertising. International Journal of Economics, Finance and Management Sciences. Vol. 7, No. 4, 2019, pp. 125-130.

doi: 10.11648/j.ijefm.20190704.14

Received: August 3, 2019; Accepted: August 26, 2019; Published: September 16, 2019

\begin{abstract}
The work deals with the development of one of the methods for simulating the logistics system of an enterprise. The aim of the article is using the approach developed by J. Forrester to build a simulation model, based on which it is possible to perform mathematical co-optimization of the production capacity, retail sale and advertising of an enterprise which produces a single product. The paper formulates a system of equations describing the logistics system of the enterprise. The model of logistical system offered by authors is original. This model has no analogues in the scientific literature. Article purpose is working out of a technique of the co-ordinated definition of optimum parametres of logistical system. Article develops a numerical method of the decision of an optimising problem which is based on system of the equations written down in shape with discrete time. The calculations of the time behavior of all rates of the logistics system (rate of production, rate of delivery), as well as the behavior of the inventory levels at the wholesale warehouse and retail are carried out. The optimization problem of determining the maximum economic efficiency is formulated and solved. In this case, production capacity and advertising costs are considered as variable parameters of the optimization problem. By numerical calculations, it is proved that there is a single point of maximum economic efficiency as a function of the planned capacity of the enterprise. Dependence on time of current profit of the enterprise is calculated and analysed.
\end{abstract}

Keywords: Logistics System, Production Capacity, Economic and Mathematical Model

\section{Introduction}

The economic task of any enterprise is to optimally expand its market niche and bring the production capacities in line with the current demand for its products [1-3]. In this case, an important role is played by marketing research of the current demand along with organizing an effective advertising campaign.

The aim of the advertising campaign is to make maximum use of the available production capacities, create conditions for their development and, in particular, their further buildup.

The problem of planning operational activities of enterprises is highlighted in numerous papers of both domestic and foreign scholars, with many of its aspects being considered [4, 5]. At the same time, the mentioned scientific works do not sufficiently cover the quantitative relationship between the parameters of the logistics system of an enterprise and the current conditions in the consumer market, namely: potential demand for its products and their consumption rate. This shortcoming of the contemporary theory complicates studying the influence of an advertising campaign on economic performance of an enterprise. In publication [6], a model which fundamentally meets the formulated requirements is proposed. It allows for a detailed consideration of conditions in the market. However, the model has a significant drawback: its application leads to unsustainable solutions in a wide range of parameters. Publication [7] presents a method to eliminate this drawback, which is based on averaging sales rates over a short time interval.

To date, there are no efficient methodologies for planning an advertising campaign of an enterprise in real-time taking into account the enterprise's logistics and market demand for its products. The methods and models developed by authors in works [8-13] are used in the article. 


\section{Propositions for the Study}

The article develops an economic and mathematical model of production activities of an enterprise taking into account both its logistics and the market demand for its products; applying the developed model to conduct a co-optimization of an enterprise's production capacity and advertising of everyday goods produced by it, with the specifics of their disposal being taken into account.

The research examines an enterprise which logistics corresponds to the scheme shown in Figure 1.

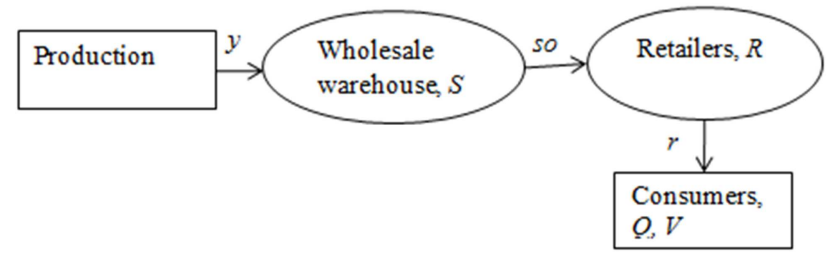

Figure 1. Scheme of the enterprise's logistics.

Working in a competitive market requires an enterprise's management to pay attention to expanding the market niche of the enterprise or at least maintaining it at an appropriate level. One of the effective means to achieve this task is conducting a periodic or continuous advertising campaign. Therefore, the construction of the model begins with mathematical description of the effect of advertising on the potential demand Q.

Let us assume that the impact of advertising on the current potential demand $Q(t)$ corresponds to the additive contribution

$$
Q(t)=Q n+Q r(t)
$$

where $Q n$ is the value of the potential demand in the absence of advertising, $\operatorname{Qr}(t)$ is the contribution of advertising to the potential demand.

We suggest that the potential demand $Q$ due to advertising is proportional to the number of consumers who have already got acquainted with the advertising of the enterprise's goods. Then the increase in the potential demand $\Delta Q r$ will be proportional to the product of the number of consumers who have not yet got acquainted with the advertising of the goods $(Q m-Q r)$ (where $Q m$ is the maximum possible number of potential consumers of the item) by the advertising costs $\Delta Z$ :

$$
\Delta Q r=\frac{1}{t z}(Q m-Q r) * \Delta Z
$$

where $\frac{1}{t z}$ is the proportionality coefficient ( $t z$ is a constant depending on the market conditions and the item considered).

Proceeding to differentials, we obtain the following equation:

$$
\frac{d Q r}{d Z}=\frac{(Q m-Q r)}{t z}
$$

Since with zero advertising costs the potential demand $Q r$ due to advertising has also the zero value $Q r=0$, equation (1) needs to be solved under the initial condition $\operatorname{Qr}(0)=0$.
Then equation (1) has the following solution:

$$
Q r(Z)=Q m *(1-\exp \{-Z / t z\})
$$

Equation (2) means that with the cost of advertising $\mathrm{Z}$ the value of potential demand due to the advertising campaign $\operatorname{Qr}(Z)$ will be achieved.

Equation (2) with $Q m=1000$ and $t z=30$ results in the dependence of the maximum value of potential demand $Q r$ on the costs for the advertising campaign $Z$ as shown in Figure 2.

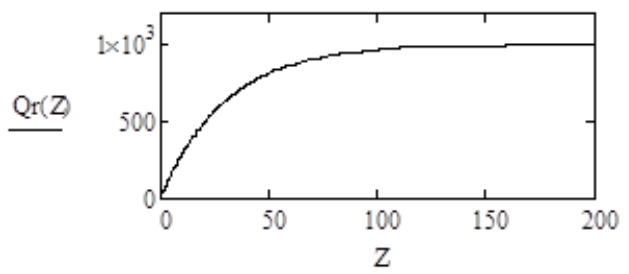

Figure 2. Dependence of the maximum potential demand $Q r$ on the advertising costs $Z$ (UAH per period of time).

Figure 2 shows the curve of the maximum potential demand Qr which will be achieved with constant advertising costs $\mathrm{Z}$ (UAH per period of time). The maximum potential demand $Q r$ cannot exceed a certain maximum value of $Q m$ with any costs. However, we will be interested not only in the maximum value achieved with the costs $\mathrm{Z}$ but also in the behavior of the potential demand.

We will consider time as a discrete variable $i(i=$ $0,1,2, \ldots, T)$. Let us study the project of the $T$ length (the planning horizon). The behavior of potential demand due to advertising campaign is described in the discrete-time model by the vector $Q_{i}$. Applying to the vector $Q_{i}$ the same reasoning which brought to formula (2), we get the following equation:

$$
Q_{i+1}=\operatorname{Qr}(Z) *(1-\exp \{-i / t r\})
$$

Formula (3) means that the contribution to the potential demand due to the advertising campaign $Q_{i}$ is described by the first-order lag model [8-10].

Let us confine ourselves to considering the advertising campaign which is defined by equations (1)-(3).

\section{Methodology}

We will formulate a system of equations which describe the logistics system of the enterprise presented in Figure 1. We assume that the enterprise is fully provided with working capital.

1. The change in the demand $Q_{i}$ for products on the market is an input impact for the enterprise whose task is to align its output with the demand

$$
r_{i+1}=n \cdot R_{i} \cdot\left(Q_{i}-V_{i}\right)
$$

where $r_{i}$ is the sales rate (unit per period of time) in the $i^{\text {th }}$ period; $n$ is the parameter which is determined by the average sales level for the previous quarter (or year); $R_{i}$ is the inventory level at the retail in the $i^{\text {th }}$ period; $V_{i}$ is the 
inventory level in the hands of consumers (not consumed yet).

2. The inventory level at the retail is determined by the recurrence formula:

$$
R_{i+1}=R_{i}+T d \cdot\left(s o_{i}-r_{i}\right)
$$

where $s o_{i}$ is the rate of delivery (units per period) from the wholesale warehouse to retailers; $T d$ is the period of discretization of the model, the time interval between decisions.

3. The level $R_{i}$ should be within the limits of $0 \leq R_{i} \leq$ $R m$, where $R m$ is the maximum possible inventory level at the retail. The requirement is described by the following formula for the rate of delivery from the wholesale warehouse to retailers:

$$
s o_{i+1}=\min \left[r_{i} \cdot\left(1+\frac{R m-R_{i}}{R m}\right), \frac{R m-R_{i}}{T d}, \frac{s_{i}}{T d}\right]
$$

where $S_{i}$ is the inventory level at the wholesale warehouse.

Publication [7] substantiates the need for averaging when performing the calculations with the proposed model:

$$
\overline{S o}_{i}=\langle s o\rangle_{i-p s}^{i}
$$

where $p s$ is the averaging time interval.

4. The production rate $y_{i}$ is determined by the following formulas:

$$
\begin{gathered}
y_{i+1}=\left(y_{i}+\frac{y m-y_{i}}{t y}\right) \cdot A\left(S_{i}\right) \\
A\left(S_{i}\right)=\left\{\begin{array}{c}
1, \text { if } S_{i}<S m-2, \\
0,5 \text { otherwise, }
\end{array}\right.
\end{gathered}
$$

where $y_{i}$ is the production capacity in the $i^{\text {th }}$ period; $y m$ is the planned value of the production capacity; $S m$ is the maximum inventory level at the wholesale warehouse. These formulas allow avoiding the overflow of the wholesale.

5. The inventory level at the wholesale warehouse $S_{i}$ is calculated using the following formula:

$$
S_{i+1}=S_{i}+T d *\left(y_{i}-s o_{i}\right)
$$

where $y_{i}$ is the rate of goods flow which goes in to the wholesale warehouse from the enterprise.

6. To determine the net income of the enterprise, the following formulas are applied:

$$
\begin{gathered}
M_{i}=(1-k p) *\left[(1-k a d) * p * r_{i}-p * c * y p_{i}-\right. \\
\left.-z S * S_{i}-z R * R m-q z \cdot z\right]-B\left(y_{i}\right) \\
B\left(y_{i}\right)=\left\{\begin{array}{c}
0, \text { if } i<1 \\
q y\left|y_{i}-y_{i-1}\right|, \text { otherwise }
\end{array}\right.
\end{gathered}
$$

where $c$ is the share of the prime cost in the price for products; $p$ is the price for a production unit; $z R, z S$ are the costs for the storage of a production unit during one period at the retail and wholesale warehouse, respectively; $k p$ is the income tax rate; $k a d$ is the value-added tax rate; $q y$ is the cost of 'including', 'excluding' a unit of production capacity.

We will perform calculations for the model (1)-(11) with the following values of its parameters:

$$
\begin{gathered}
R m=80, t y=15, \mathrm{Q}=1200, \mathrm{k} 1=0,33, \mathrm{dT}=1 \\
t z=30, t Q=10, Q m=1000, Q n=1000, q S=0,88, Z=54 \\
k 2=0,2, S_{0}=100, S m=200, n=0,00005, y m=6, q z=035 \\
\mathrm{kp}=0,25, \mathrm{kad}=0,06, \mathrm{c}=0,6, \mathrm{p}=10, \mathrm{z}=0,3, z 1=0,006
\end{gathered}
$$

Guidance of enterprise wants to define the optimal parameters of the logistic system. As a criterion of optimality it is decided to choose a complete income which the enterprise will get for a year:

$$
F 1(R m, y m, Z)=\sum_{i=1}^{365} M_{i} \rightarrow \max
$$

In other words, to find a maximum of objective function (13) at such variation parameters: $y m$ is a planned value of power of production; $R m$ is a maximal value of capacity at the retail, $Z$ are expenses on advertising in one period (there are expenses identical in every period).

Limitations for the optimization task (13) is the system of equalizations (1)-(11).

Previous experience shows that an economic result $(F 1)$ substantially depends on the initial filling at the retail, i.e. from a value $R_{0}$. On technological reasons, $R_{0}$ can have such three values $R_{0}=10,40,60$.

Therefore optimization task (13) must be separately decided for three values $R_{0}$.

\section{Results of Calculations}

The solution of an optimising problem at $R_{0}=10$ will be the following.

$$
\left(\begin{array}{c}
R m_{o p t} \\
y_{o p t} \\
Z_{o p t}
\end{array}\right)=\left(\begin{array}{c}
84,3 \\
6,46 \\
56
\end{array}\right)
$$

Thus the full profit will make

$$
F 1\left(R m_{\text {opt }}, y_{\text {opt }}, Z_{\text {opt }}\right)=10311,7
$$

Figure 3 illustrate the discovered optimum solution.
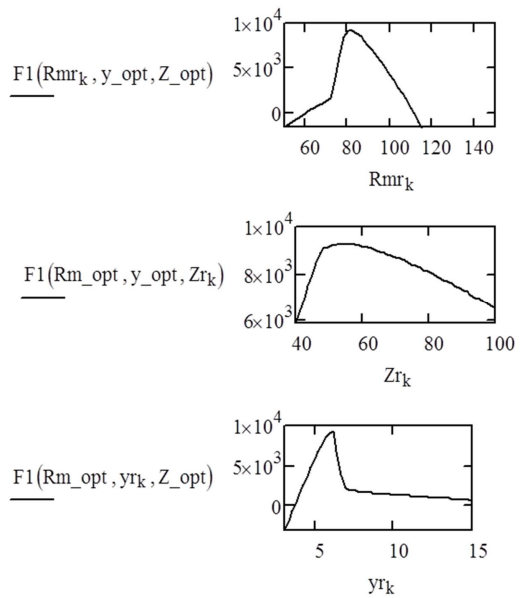

Figure 3. Graphic demonstrating of an optimum solution (14), (15) for $R_{0}=10$. 
Modifications of full profit on one of parametres are shown in Figure 3 at the fixed values remaining two in a case when initial filling at the retail is equal to 10 (commodity units).

The solution of an optimising problem at $R_{0}=40$ will be the following

$$
\left(\begin{array}{c}
R m_{\text {opt }} \\
y_{\text {opt }} \\
Z_{\text {opt }}
\end{array}\right)=\left(\begin{array}{c}
90 \\
7,1 \\
49
\end{array}\right)
$$

Thus

$$
F 1\left(R m_{\text {opt }}, y_{\text {opt }}, Z_{\text {opt }}\right)=14258,3
$$

Similarly, the solution of an optimising problem at $R_{0}=60$ will be such

$$
\left(\begin{array}{c}
R m_{\text {opt }} \\
y_{\text {opt }} \\
Z_{\text {opt }}
\end{array}\right)=\left(\begin{array}{c}
105 \\
8,7 \\
64
\end{array}\right)
$$

Thus

$$
F 1\left(R m_{\text {opt }}, y_{\text {opt }}, Z_{\text {opt }}\right)=16419,4
$$

For descriptive reasons we will present the received outcomes in the form of the Table 1:

Table 1. Dependence of full profit of the enterprise for a year on initial filling at the retail $\left(R_{0}\right)$.

\begin{tabular}{ll}
\hline $\boldsymbol{R}_{\mathbf{0}}$ & $\boldsymbol{F 1}\left(\boldsymbol{R} \boldsymbol{m}_{\text {opt }}, \boldsymbol{y}_{\text {opt }}, \boldsymbol{Z}_{\text {opt }}\right)$ \\
\hline 10 & 10311,7 \\
40 & 14258,3 \\
60 & 16419,4 \\
\hline
\end{tabular}

Comparison of the received outcomes shows essential dependence of economic outcome on initial filling at the retail. To understand it we will fulfil detailed calculation of dynamics of basic indicators of the logistical system. Dynamics of the basic rates of the logistical system is shown in Figure 4.

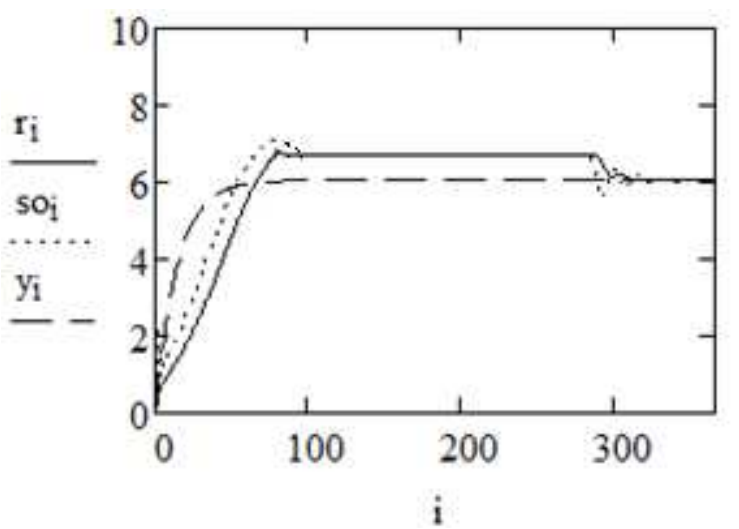

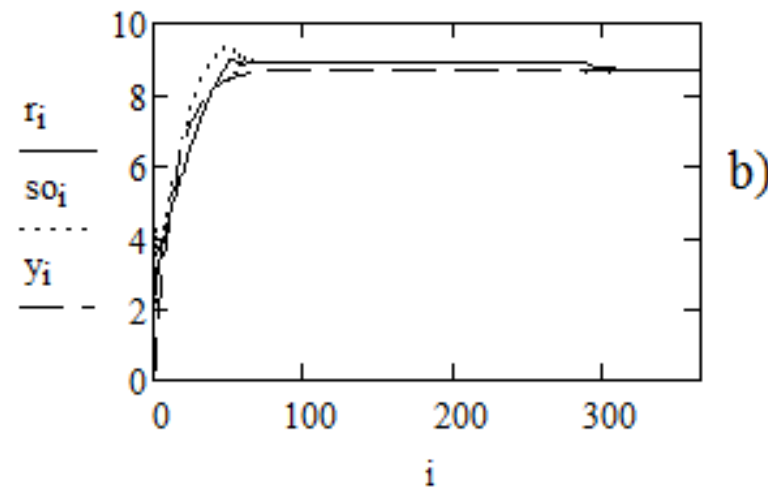

Figure 4. Dynamics of the basic rates: a) for $R_{0}=10$, b) for $R_{0}=60$.

From Figure 4 it is visible that at $R_{0}=60$ absolute values of all rates are much more. So the summarized amount of the goods sold for year will make $\sum r=2286,3$ (for $R_{0}=10$ ) and $\sum r=3119,9$ (for $R_{0}=60$ ). Such difference in number of the goods realised for a year can be explained with the help Figure 5. So from comparison of optimum solutions (14) and (16), we see that

$$
\begin{aligned}
& R m_{o p t}=84,3, \text { for } R_{0}=10 \\
& R m_{o p t}=105 \text { for } R_{0}=60
\end{aligned}
$$

And from Figure 5, it is visible that current values of the goods at the retail $R_{i}$ are near to corresponding maximum values $R m_{\text {opt }}$.
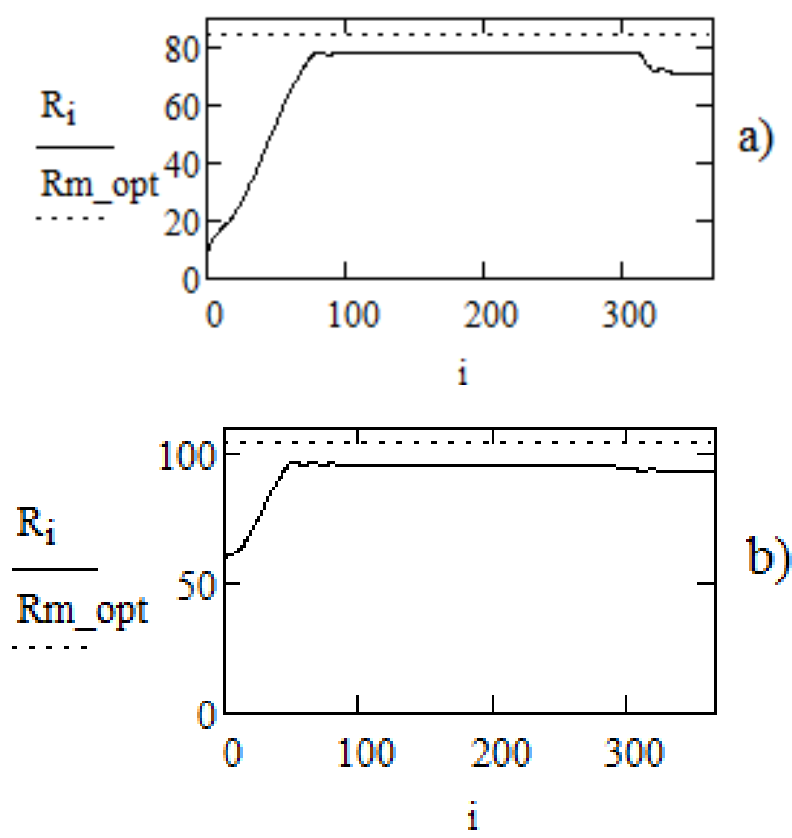

Figure 5. Dynamics of cash stocks of the goods at the retail: a) for $R_{0}=10$, b) for $R_{0}=60$.

But as appears from the equation (4), current values of rate of sales $r_{i}$ are defined by value $R_{i}$ (as one of the factors).

One more contribution to total profit is caused by quantity of the goods at the wholesale warehouse $\mathrm{S}_{\mathrm{i}}$ (Figure 6). 


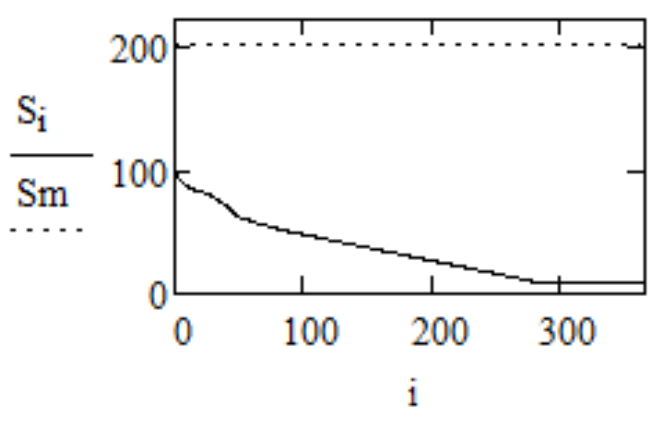

a)

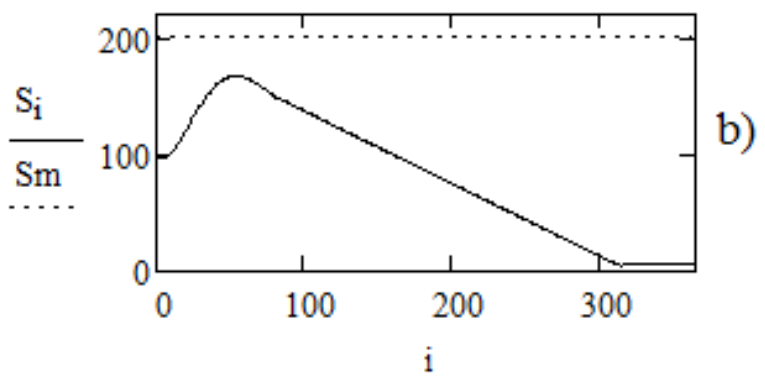

Figure 6. Dynamics of available supplies of commodity at the wholesale warehouse $S_{i}:$ a) for $R_{0}=10$, b) for $R_{0}=60$.

From the formula (10), it is visible that in model the following contractual form of calculations with a wholesale warehouse is accepted: the enterprise pays only for actual quantity of the goods at the wholesale warehouse. Therefore greater amount of commodity at the wholesale warehouse (for $R_{0}=10$ ) requires large expenses on storage.

Let's compare current profit of the enterprise at various values of $R_{0}$ (Figure 7).
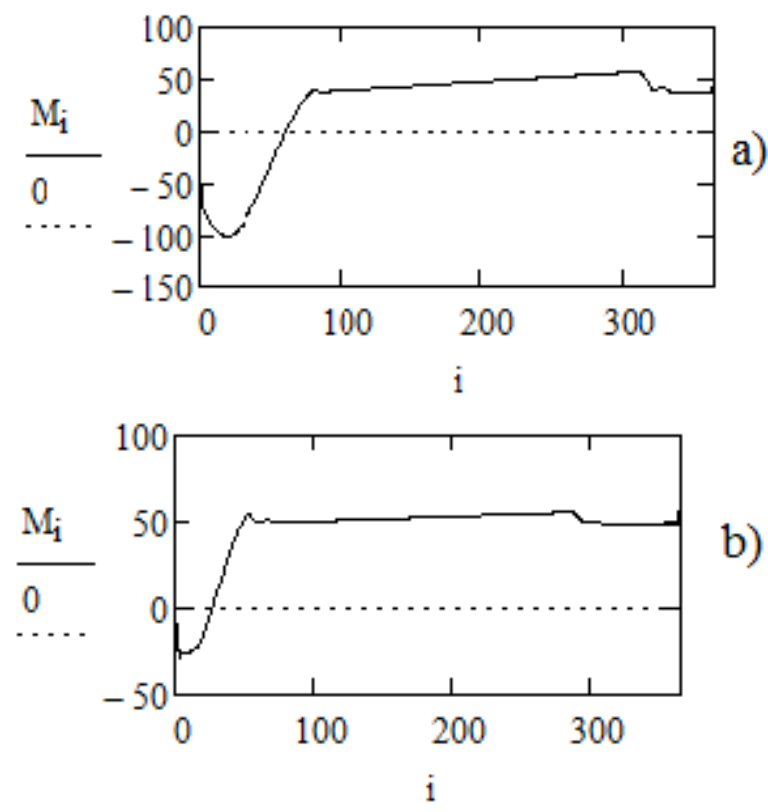

Figure 7. Dynamics of current profit of the enterprise: a) for $R_{0}=10, b$ ) for $R_{0}=60$.

The initial stage of work demands attention. At $\mathrm{R}_{0}=10$ in the beginning robots, there is a considerable period $(0 \leq \mathrm{i} \leq$ $60)$ in which current value of profit accepts considerable negative values (up to -100). It follows from the formula (10), that value of current profit of the enterprise is basically defined by a parity of rate of sales $r_{i}$ and rate of manufacture $y_{i}$. Comparison of initial rates for the specified period is shown in Figure 8.
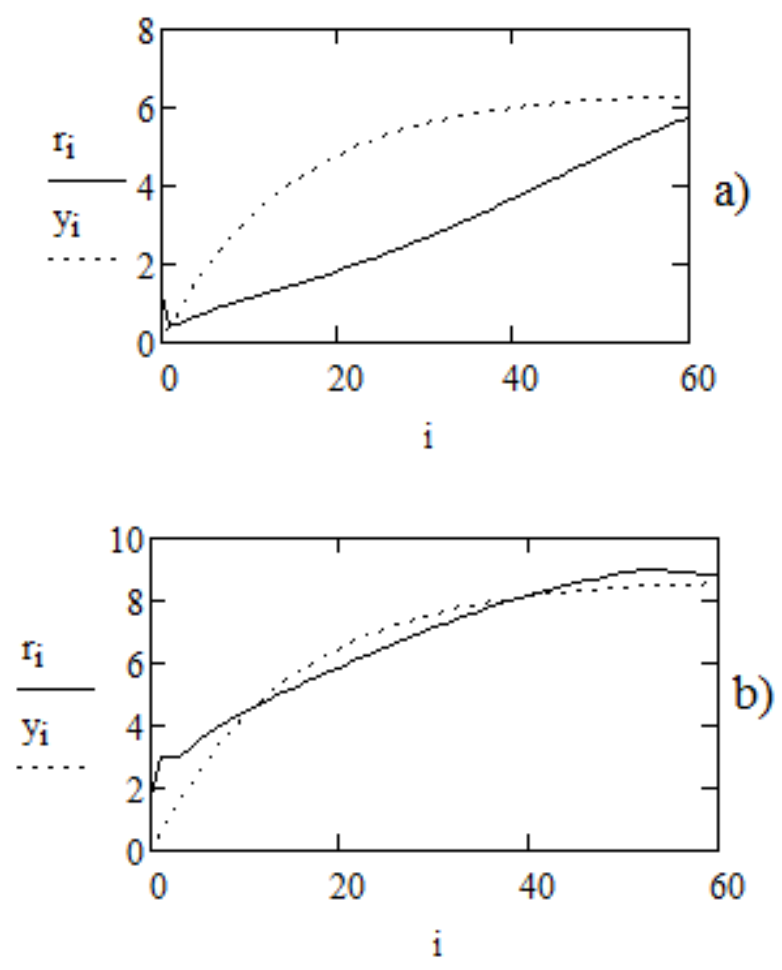

Figure 8. Dynamics of rate of sales $r_{i}$ and rate of production $y_{i}:$ a) for $R_{0}=10$, b) for $R_{0}=60$.

The Figure 8 taking into account the formula (10) explains behavior of current profit of the enterprise, that shown in Figure 7.

\section{Conclusions}

Thus, in the article, a model of the enterprise logistics system is developed. Unlike the existing models, the proposed one allows to perform co-optimization of an enterprise's production capacity and retail sales, i. e., those links that directly determine the production and sale of goods and determine the operation of all other links of the logistics system using a closed system of equations. The model does not consider movement of circulating assets. Besides, in model the part of logistical system of the enterprise is considered only. Behind model frameworks there was a market of raw materials and raw materials warehouse. These problems should be studied in the more general model that is supposed as the purposes of the further researches.

The model does not consider movement of circulating assets. Besides, in model the part of logistic system of the enterprise is considered only. Behind model frameworks there was a market of raw and a raw warehouse. These problems should be studied in more general model that is supposed as the purposes of the further researches. 


\section{References}

[1] Pedchenko, H. C (2011). Application of economic and mathematical methods at strategic management in potential of development of manufacture. The scientific bulletin of the Poltava university of economy i trade, 2 (47), 88-91.

[2] Voronov, V. A. \& Marıýta, A. N. (1997). A method of optimisation of a way of manufacture. Informationmathematical models in economy and management. Dnepropetrovsk: Science and education, 1997, 12-15.

[3] Skrınkovski1, R. M. (2015). Diagnostics of trading activity of manufacture. Business inform, 7, 201-205.

[4] Gvozdetsky, I. B and Ostapchuk O. V (2011). The analysis of approaches to modelling of managerial processes by the industrial enterprise. Business inform, 5 (1), 79-80.

[5] Olejnik, C. B (2015). Scenary planning of processes of updating of the basic means of the industrial enterprises. Business inform, 9, 174-179.

[6] Mountain, And. A, Kolpakova, And. $\Gamma$ and Lokshin B. Ja (1998). Dynamic model of process of manufacture, storage and sale of the goods of daily demand. News of the Russian Academy of Sciences. The theory and control systems, 1, 144148 .

[7] Sherstennikov, Ю. B (2013). Modelling of development of small enterprise in the conditions of the competitive market. Business inform, 7, 129-135.
[8] Sherstennikov, Ю. B and Porohnja V. M (2017) Methodological approach to modelling of time parametres of development of structure and properties of small enterprise. The state and regions. A series: Economy and business. 2, 2633.

[9] Sherstennikov, Ю. B and Kasjan, With. Я (2016). Modelling of logistics and the coordination of rate of manufacture of the goods with rate of realisation. Economy problems. 3, 314-320.

[10] Sherstennikov J. V., T. M. Rudjanova and V. Ju. Britska. (2018). Modelling optimisation of capacity of the enterprise. Business inform, 6, 186-192.

[11] Sherstennikov, Ю. B. And Rudjanova, T. M (2014). Modelling of mechanisms of influence on rates of sales of production of the enterprise. Actual problems of economy, 1, 551-559.

[12] Sherstennikov, Yu V. (2018) Modeling Optimization of an Enterprise's Production Capacity and Retail Sales. Business inform, 6, 186-192.

[13] Sherstennikov, Ю. B. (2013). Modelling of oligipoly taking into account the logistics, the limited release and enterprise advertising. Business inform, 10, 135-141.

[14] Forrester, Jay W. (1958), Industrial DYNAMICS - A Major Breakthrough for Decision Makers, Harvard Business Review, Vol. 36, № 4, pp. 37-66 (July-August 1958).

[15] Forrester, J. (1971). Bases of cybernetics of the enterprise (Industrial dynamics), Moscow, 1971, $340 \mathrm{p}$. 